\title{
Adiabatic wall temperature and heat transfer coefficient influenced by separated supersonic flow
}

\author{
Alexander Leontiev ${ }^{1}$, Sergey Popovich ${ }^{1,},{ }^{*}$ Mark Strongin ${ }^{1}$ and Yurii Vinogradov ${ }^{1}$ \\ ${ }^{1}$ Institute of Mechanics, Lomonosov Moscow State University, 1, Michurinsky Pr., Moscow, 119192, \\ Russia
}

\begin{abstract}
Investigations of supersonic air flow around plane surface behind a rib perpendicular to the flow direction are performed. Research was carried out for free stream Mach number 2.25 and turbulent flow regime $-\operatorname{Re}_{\mathrm{x}}>2 \cdot 10^{7}$. Rib height was varied in range from 2 to $8 \mathrm{~mm}$ while boundary layer thickness at the nozzle exit section was about $6 \mathrm{~mm}$. As a result adiabatic wall temperature and heat transfer coefficient are obtained for flow around plane surface behind a rib in contrast with the flow around plane surface without any disturbances.
\end{abstract}

\section{Introduction}

One of the major problems in high speed vehicles engineering is the accuracy of experimental data obtained in supersonic wind tunnels while its extrapolation to the real flight conditions. Flight speed increasing over $0.4 \cdot \mathrm{M}$ results in the requirement for accounting of compressibility effect $[1,2]$. Flow deceleration from supersonic speed to the zero-order meaning on the wall causes increased flow kinetic energy transforming into heat in comparison with subsonic flows.

Heat transfer factor $h$ for supersonic gas flow around the wall is evaluated by means of specific heat flow rate $q$ divided by the difference between adiabatic wall temperature $T_{a w}$ and the measured wall temperature $T_{w}$ :

$$
h=\frac{q}{T_{a w}-T_{w}}
$$

One of the main problems in the equation (1) is definition of adiabatic wall temperature $T_{a w}[3,4]$. In engineering applications it is defined by means of temperature recovery factor $r$, total temperature $T_{0}$, Mach number $\mathrm{M}$ and the ratio of specific heats $\gamma$ :

\footnotetext{
*Corresponding author: pss1@mail.ru
} 


$$
T_{a w}=\frac{T_{0} \cdot\left(1+r \cdot \frac{\gamma-1}{2} \cdot \mathrm{M}^{2}\right)}{1+\frac{\gamma-1}{2} \cdot \mathrm{M}^{2}}
$$

The physical meaning of temperature recovery factor $r$ is that it shows a part of the flow kinetic energy that is transformed to the heat on the wall [1-4]. It is defined by means of adiabatic wall temperature $T_{a w}$, total temperature $T_{0}$ and static temperature $T$ :

$$
r=\frac{T_{a w}-T}{T_{0}-T}
$$

There is a theoretical relation for recovery factor - it depends on the working medium Prandtl number, i.e. its viscosity, specific heat and thermal conductivity: $r=\operatorname{Pr}^{n}$. Numerous experimental research for air flows [5] show that for a turbulent boundary layer in supersonic flow around the plate and along the cylinder recovery factor $r$ lies in the range $0.885 \pm 0.01$. Theoretical relation for recovery factor in turbulent conditions is: $r=\sqrt[3]{\mathrm{Pr}}$. This relation was experimentally proven for air in and around $\operatorname{Pr}=0.7$. At the same time some researchers consider influence of recovery factor from Reynolds, Mach and Prandtl numbers, injection/suction into/from the boundary layer, shape and relief of streamlined surface [5-11]. These results show that recovery factor can significantly differ from the mentioned approximation.

High influence of heat transfer coefficient from temperature recovery factor is also intensified by low gas temperature in most supersonic wind tunnels. In addition if researched Mach number is not high (less than $\mathrm{M}=3$ ) then temperature difference between adiabatic wall temperature and wall temperature is not high [4]. Therefore, mistakes in temperature recovery factor cause high uncertainties in heat transfer data [12].

For flow around simple bodies (plane surfaces, cylinders, cones) adiabatic wall temperature is defined with the use of theoretical meaning for recovery factor as a function of Prandlt number. However, when the flow with a boundary layer separation is considered (behind ribs, dimples, holes) then it is difficult to define adiabatic wall temperature and it is often changed for the flow stagnation temperature. Such approach results in high errors in defining heat transfer coefficient - up to $50 \%$. The goal of this research was applying of an unsteady state methodology for adiabatic wall temperature acquisition in aerodynamic experiment together with heat transfer coefficient definition.

\section{Experimental apparatus, instrumentation and technique}

Experiments have been conducted in supersonic wind tunnel during its launching $[12,13]$. Flow velocity in the working area was changed with the use of plane variable supersonic nozzle in range of Mach numbers $2.0 \div 3.0$. Stagnation pressure was up to $7 \mathrm{~atm}$. Stagnation temperature changed from 278 to $298 \mathrm{~K}$. Maximum gas flow rate was about $5 \mathrm{~kg} / \mathrm{sec}$.

Working area has a rectangular cross-section $70 \mathrm{~mm}$ width and $90 \mathrm{~mm}$ height (Fig. 1). For the purpose of experimental observation optical glass windows were installed on side walls of the working area. Flow visualization was made with schlieren photography thus providing an opportunity of shock waves observation for separation flow behind the rib. As an experimental model a plate made of plexiglass was taken. This material has a low thermal conductivity coefficient $k=0.19 \mathrm{~W} /(\mathrm{m} \cdot \mathrm{K})$ thus providing an assumption of heat insulated surface. The model was mounted on the lower side of the working area in parallel 
with the main flow (Fig. 1). Width of the model fitted the working area $-70 \mathrm{~mm}$, its length was $200 \mathrm{~mm}$. On the lower side of the channel in front of the model a rib was placed perpendicularly to the flow direction. Rib height was changed from 2 to $8 \mathrm{~mm}$. Boundary layer thickness in the region of rib placement was about $6 \mathrm{~mm}$ (for flow around plane surface without any disturbances). Reynolds number was calculated for boundary layer length from the nozzle throat and its meaning was $\operatorname{Re}_{x} \geq 2 \cdot 10^{7}$, which corresponds to turbulent flow regime.

In order to measure static pressure experimental model was drained along the central line. Through this perforation air bleed was taken to the static pressure probe. Stagnation parameters were measured in settling chamber of the wind tunnel: temperature - with the use of two insulated chromel-alumel thermocouples, static pressure - with the use of probes Honeywell ML-300PS2PC. Wall temperature of the experimental model was recorded by 6 thermocouples pressurized on the wall surface.

Automation program was made in LabView. Data from all the probes was taken to the signal conditioning unit NI SCXI-1303, then it goes through the instrumentation amplifier SCXI-1102 (thermocouple) and SCXI-1102B (pressure probe) and finally comes into the analog-digital converter NI PCI-6220.

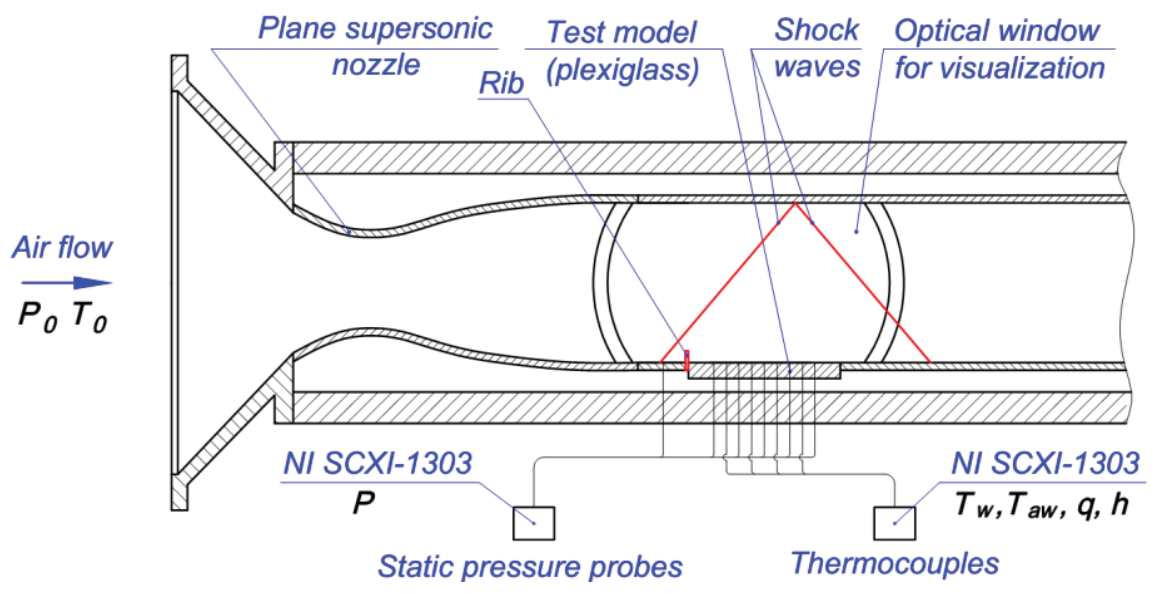

Fig. 1. Experimental apparatus and instrumentation schematic model

The methodology for adiabatic wall temperature acquisition implies registering wall temperature during launching of the wind tunnel. Then the heat flux rate is calculated from the registered temperature time history $T_{w}$, plexiglass properties: density $\rho$, thermal conductivity $k$ and specific heat $C$ (4). Further on the heat flux rate can be presented in dimensionless form so that it could be linearly extrapolated to the zero heat flux meaning $[3,4,15]$. The calculated wall temperature at the zero heat flux rate is equal to the adiabatic wall temperature. Finally, Stanton number can be derived from heat flux rate and difference between measured wall temperature and calculated adiabatic wall temperature.

$$
q=\frac{\sqrt{\rho k C}}{\sqrt{\pi}} \int_{0}^{t} \frac{\frac{d T_{w}(\tau)}{d \tau}}{(t-\tau)^{1 / 2}} d \tau
$$

Measurement uncertainties of the main parameters were calculated for $95 \%$ confidence interval [12]: $\pm 1.2 \%$ for Mach number, $\pm 2.7 \%$ for Reynolds number, $\pm 0.8 \%$ for temperature recovery factor, $\pm 9.6 \%$ for heat transfer coefficient. 


\section{Results and discussion}

The results show that in the separated region behind the rib adiabatic wall temperature is lower than the wall temperature (Fig. 2, a). Total temperature after launching is almost constant during the experiment. Wall temperature is lowering and in the limit it will reach its adiabatic meaning but during 90 seconds of this experiment it didn't happen.

Difference between total temperature and adiabatic wall temperature along the model length is presented on Fig. 2, b). For flow around plane model this meaning is about 17 degrees. For separated flow behind the rib the difference is higher: from 21 degress for 2 $\mathrm{mm}$ rib height to 27 degrees for $8 \mathrm{~mm}$ rib height.

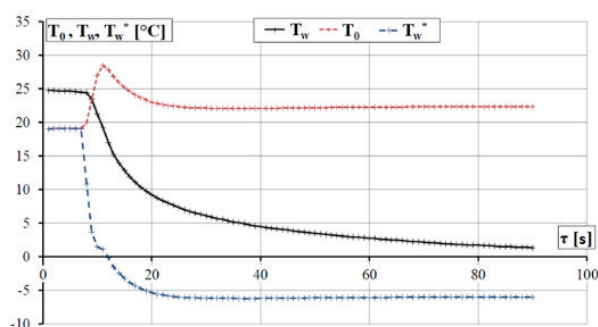

a)

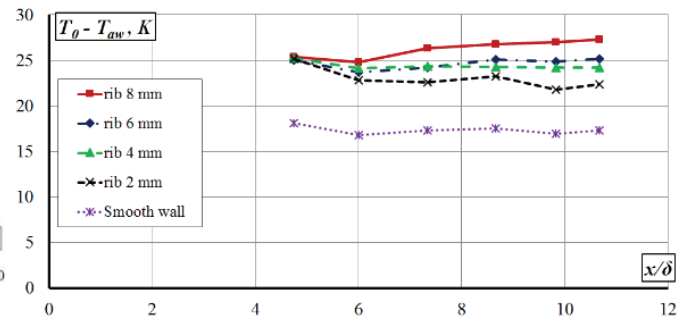

b)

Fig. 2. a) Total temperature, wall temperature and adiabatic wall temperature changing during launching of the wind tunnel; b) Difference between total temperature and adiabatic wall temperature for flow around smooth wall $\left(\mathrm{M}_{0}=2.25\right)$ and flow behind the rib of varied height $(2,4,6$ and $8 \mathrm{~mm})$

Temperature recovery factor is decreased in the region of boundary layer separation behind the rib (Fig. 3): from 3.6\% for $2 \mathrm{~mm}$ rib height up to $7.7 \%$ for $8 \mathrm{~mm}$ rib height in comparison with the flow around plane model. While going down from the rib the recovery factor is decreasing in proportion to rib height.

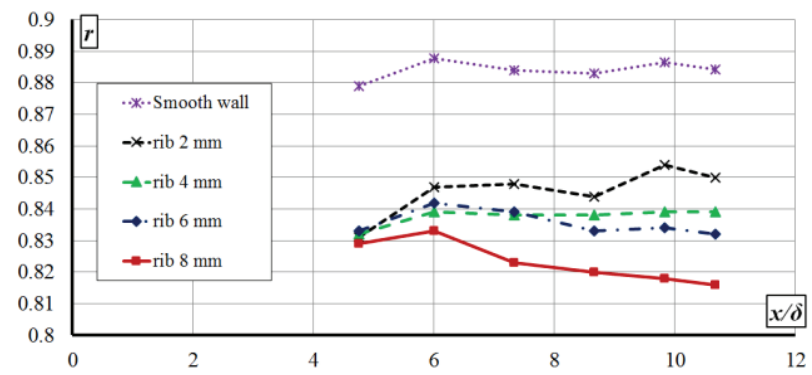

Fig. 3. Temperature recovery factor for flow around smooth wall $\left(\mathrm{M}_{0}=2.25\right)$ and flow behind the rib of varied height $(2,4,6$ and $8 \mathrm{~mm})$

Maximum increasing of heat transfer coefficient was about $34 \%$ for $8 \mathrm{~mm}$ rib height, while the highest $30 \%$ meaning for most thermocouples along the model length was registered for $6 \mathrm{~mm}$ rib height (Fig. 4). Comparison of the regimes with and without the rib was taken for the same input Mach number $\left(\mathrm{M}_{0}=2.25\right)$. Most of the thermocouples registered $20 \%$ increasing heat transfer rate for separated flow in comparison with the smooth model flow. 


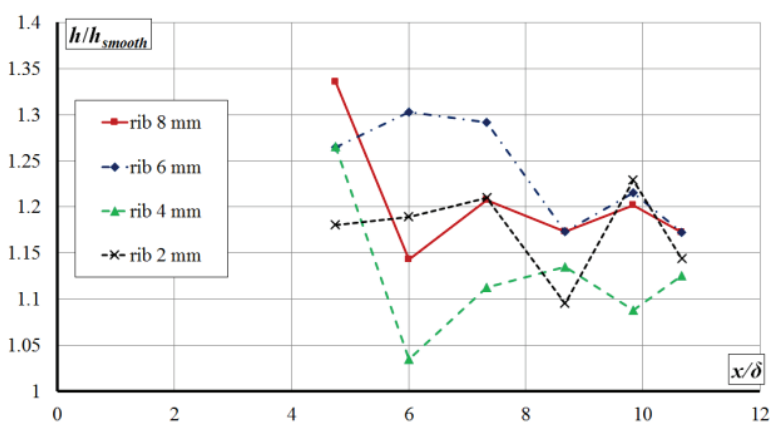

Fig. 4. Heat transfer coefficient for flow behind the rib (rib heights 2, 4, 6 and $8 \mathrm{~mm}$ ) divided by the coefficient for flow around smooth wall

\section{Conclusions}

Experimental results are presented for boundary layer separation influence on adiabatic wall temperature and heat transfer coefficient in supersonic flow around plane surface. Separated flow was generated by means of a rib in front of the plane model. Temperature recovery factor is decreased in separation region by $3.6 \%$ for $2 \mathrm{~mm}$ rib height up to $7.7 \%$ for $8 \mathrm{~mm}$ rib height in comparison with the flow around smooth surface. Heat transfer coefficient is increased in the separation region by up to $34 \%$ compared to smooth model flow.

The research was supported by Russian Science Foundation (Project 14-19-00699).

\section{References}

1. S.S. Kutateladze, A.I. Leontiev, Heat Transfer, Mass Transfer, and Friction in Turbulent Boundary Layers (Taylor and Francis, New York, 1990)

2. H. Schlichting, Boundary layer theory (McGraw-Hill, New York, 1968)

3. D.L. Schultz, T.V. Jones, AGARDograph, 165 (1973)

4. J.R. Hayes, R.D. Neumann, AIAA, Tactical Missile Aerodynamics, 142 (1992)

5. H.A. Johnson, M.W. Rubesin, Transactions of the ASME (1948)

6. P.F. Brinich, NACA TN 4213 (1958)

7. B.J. Garland, J.R. Hall, NACA RM, L57L09 (1958)

8. G.E. Gadd, W.F. Cope, J.L. Attridge, A.R.C. Technical Report, 3148 (1960)

9. Yu.V. Baryshev, Yu.A.Vinogradov, A.I. Leont'ev, V.I. Rozhdestvenskii, Fluid Dynamics, 7, 2, 303 (1972)

10. A.I. Leontiev, Yu.A. Vinogradov, S.M. Bednov, A.N. Golikov, I.K. Ermolaev, E.V. Dilevskaya, M.M. Strongin, Exp. Thermal Fluid Sci., 26, 487-497 (2002)

11. A.I. Leont'ev, V.G. Lushchik, A.E. Yakubenko, Fluid Dynamics, 43, 5 (2008)

12. R.J. Moffat, Experimental and Flud Science, 3-17 (1988)

13. S.S. Popovich, K.S. Egorov, Yu.A. Vinogradov, Proceedings of 15th International Heat Transfer Conference, IHTC-15-8962, 11 (2014)

14. S. Popovich, M. Strongin, Yu. Vinogradov, A. Zditovets, Proceedings of the 8th International Symposium on Turbulence, Heat and Mass Transfer, 865-868 (2015)

15. D.J. Mee, H.S. Chiu, P.T. Ireland, Int. J. of Heat and Mass Transfer, 45, 3287-3297 (2002) 